\title{
Epidemio-clinical Profile of Stunting in School Children of an Urban Community in Cameroon
}

\author{
Georges Pius Kamsu Moyo ${ }^{1, \text { *, Ivan Fred Kamsi Djomkam² }}$ \\ ${ }^{1}$ Faculty of Medicine and Biomedical Sciences, University of Yaoundé I, Yaoundé, Cameroon \\ ${ }^{2}$ SOA, District Hospital, Yaoundé, Cameroon
}

Email address:

kamsuzicfried@yahoo.fr (G. P. K. Moyo)

${ }^{*}$ Corresponding author

\section{To cite this article:}

Georges Pius Kamsu Moyo, Ivan Fred Kamsi Djomkam. Epidemio-clinical Profile of Stunting in School Children of an Urban Community in Cameroon. American Journal of Pediatrics. Vol. 6, No. 2, 2020, pp. 94-97. doi: 10.11648/j.ajp.20200602.15

Received: February 7, 2020; Accepted: February 20, 2020; Published: March 6, 2020

\begin{abstract}
Background: Stunting in children results from a defective growth. Our objective was to describe the epidemiological and clinical profiles of stature growth delay in school children of an urban community in Cameroon. Methods: This was a cross-sectional study carried out on primary and secondary school children aged between 8 to 15 years, from January to June 2015 in Yaoundé, Cameroon. The study involved 1442 children of which 79 presented stature delay. Results: The mean age was 12 years (IQR: 11-13ans). The prevalence of stunting was 5.47\% (95\% CI: 3.59 to 5.87) Among which 48 $(60 \%)$ of affected children were in secondary school, $41(51.89 \%)$ were of female sex, $54(68.35 \%)$ were aged between 11 and 13years old, $49(62 \%)$ came from families with average or limited socioeconomic level out of which $30(62 \%)$ had limited or poor diet, $76(96.2 \%)$ had normal BMI, $26(33 \%)$ had bone size abnormalities, $10(12.65 \%)$ had delayed puberty, and $4(5 \%)$ had a chronic disease. Conclusion: Stunting occurs among school children in the urban communities of Yaoundé in Cameroon, with considerable percentages of affected children diagnosed for the first time in secondary school, and coming from families with low socioeconomic level, having poor diet. Regular measurements of anthropometric parameters and holistic assessment may help for prevention.
\end{abstract}

Keywords: Stunting, Short Stature, Growth, Cameroun

\section{Introduction}

Growth from a morphological point of view may be defined as an increase in size. The determinants of child growth rate are multifactorial including nutrition, chronic diseases, endocrine and psychological factors [1]. According to Tanner et al in 1986, growth can be considered as a mirror image of the society and height as "a proxy for health" $[2,3]$. Children with stature growth delay can be found in all countries worldwide, with a global prevalence around $25 \%$ in the year 2000 [4]. In Cameroon, the prevalence of childhood stunting increased from 23\% to 29\% between 1991 and 1998 [5]. Among the various phases of growth, the childhood phase seems to be the most determinant in African children and depends so much on adequate nutrition according to Karlberg et al $[6,7]$. Stature growth delay may be under diagnosed due to non-systematic or erroneous anthropometric assessments at routine visits, whereas present in even some supposedly healthy children [8]. Growth retardation may be associated with cognitive and physical disadvantage, considerable morbidity and mortality $[8,9]$. The present study aims at describing the epidemiological and clinical aspects of stunting in some school children of the urban communities of Yaoundé, the capital city of Cameroon.

\section{Methodology}

A cross-sectional study was carried out in primary and secondary schools of the urban community of Yaoundé, Cameroon. For six months, from January to June 2015, children aged 8 to 15 years, registered in selected schools and whose parents' authorizations were obtained, were included in the study. Random cluster sampling was done with primary statistical unit being the school (cluster) and the secondary statistical unit being the student. School selection 
was done from a list of educational institutions obtained from regional delegations of secondary and basic educations for the year 2015. The draw was conducted so as to have equal probability for each institution. As such, 10 schools were selected out of 1471 . The minimal sample size estimated was 1325 children, with a confidence interval at 95\% and 5\% precision. The number of students who took part in the study was 1442. Enrolled children were submitted to a data collection sheet. The enquiries comprised demographic indicators, health status, socioeconomic level, nutritional assessment, psycho-environmental investigation and anthropometric measurements. Collected data was then transferred into a software-conceived data base with Epi Data and analyzed using STATA version 12.0. Bi variate analysis was done with Student's test or $\mathrm{Chi}^{2}$ according to the variable. Fischer's test served for analyzing small qualitative variables.

\section{Results}

We worked on a sample of 1442 children. The mean age was 12 years (IQR: 11-13ans): 13 years for secondary school children (IQR: 12-14ans) and 10 years for primary school children (IQR: 9-11ans). Children of female sex represented $55.43 \%$ (CI: 52.62 - 58.22) of the series while boys accounted for $44.57 \%$ (CI: $41.78-47.38$ ). The children in this survey were mainly $(57.72 \%)$ from families with average socio-economic level. Fifty-two percent $(52 \%)$ of school children had good diet, 31\% had limited diet and 17\% had poor diet according to food safety criteria defined by World Food Program (WFP).

We found 79 children with heights below -2 Standard Deviation (SD), thus a prevalence of 5.4\% (95\% CI: 3.59 to 5.87) of children presenting stature growth delay. Children aged 11 to 13 years were most affected (Figure 1). The Greater proportion $(60 \%)$ of the children with stunting was among secondary school children.

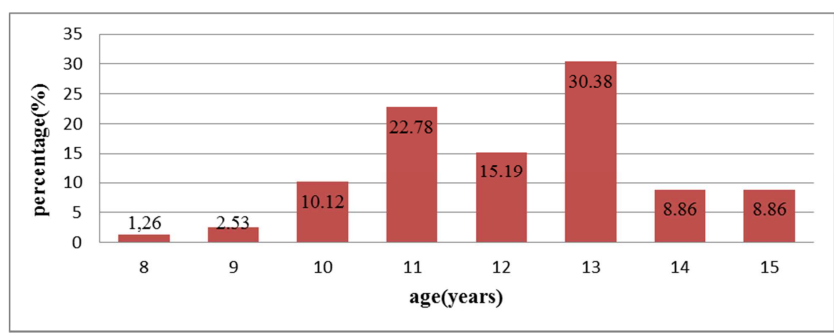

Figure 1. Age distribution of schoolchildren with stature delay.

Children of female sex represented $51.9 \%$ (41) of children with stunting. Most children presenting short stature originated from the district of Yaoundé 1: 29 (36.7\%), followed by Yaoundé 6: 27 (34.17\%). No case was recorded in the district of Yaoundé 5. The majority of children with short stature were from families with average socioeconomic level $49(62 \%)$ among which $62 \%$ had limited or poor diet while $28 \%$ had good diet according to WFP. Ninety-five point two percent $(96.2 \%)$ of children with stunting had normal BMI (-1DS $<$ BMI $<1 \mathrm{DS})$ and $4.8 \%$ of them, being girls were overweight ( $+1 \mathrm{DS}<\mathrm{BMI}<+2 \mathrm{DS})$.

Table 1. Distribution of students according to socioeconomic level.

\begin{tabular}{lll}
\hline Socioeconomic level & Number & Percentage (\%) \\
\hline High & 454 & 31.48 \\
Average & 871 & 60.40 \\
Low & 98 & 6.79 \\
No response & 19 & 1.31 \\
Total & 1442 & $\approx 100$ \\
\hline
\end{tabular}

Thirty-three percent $(33 \%)$ of children with short stature had abnormal body segments suggestive of bone abnormalities. Delayed puberty according to Tanner's classification was found in $12.7 \%$ ( 3 girls and 7 boys), 3\% reported having chronic kidney disease, $1.5 \%$ were chronic heart disease carriers and sickle cell anemia occurred in $0.5 \%$. The proportion of children with stature growth delay affected by chronic disease was $5 \%$.

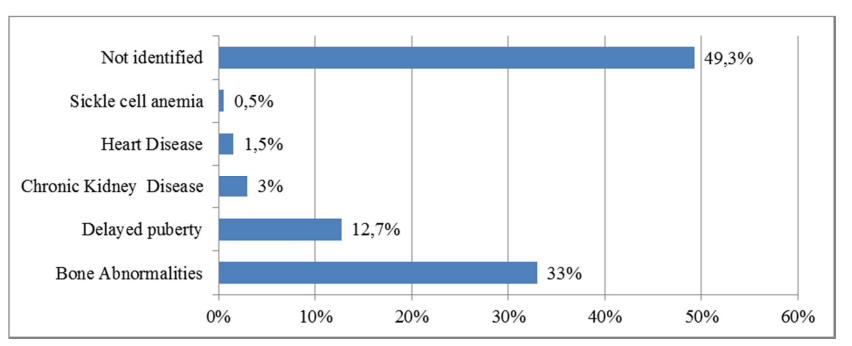

Figure 2. Distribution of associated health hazards.

\section{Discussion}

The predominant age group affected with stunting was from 11 to 13 years, with more than $68 \%$ of them being secondary school children. This result was similar to that described in the literature which states that the incidence of stature growth delay within various age groups tends to increase with age. For example, El Hioui et al described an increase from $4.4 \%$ between 6 and 10 years to $14.8 \%$ between 11-16 years [4]. From a physiological point of view, the cause could be multifactorial, including reduced or varying hormone influences on the growth process $[9,10$, 11]. This may seem paradoxical, given the age range which rather corresponds to puberty. However, puberty delay found in $12.5 \%$ of children with stunting in our series may as well be a possible explanation to the results obtained. On the other hand, late diagnosis and inadequate management could be another reason.

Short stature was slightly predominant in girls and is consistent with results obtained by some other authors [12, $13,14]$. The difference could be due to genetic constitution at the basis of hormone synthesis and tissue development, which differs for male and female gender [14].

We recruited 1442 school children, out of which 79 had heights below -2 Standard Deviation (SD), giving a prevalence of $5.47 \%$ for stunting in our series. This prevalence is lower than those found in some West African countries [11]. In effect, the difference in study settings, with 
some of them carried out in rural areas may be a justification, given that the level of education, nutritional potential and hence growth rate may be affected by geographical context.

Sixty-two percent $(62 \%)$ of children presenting short stature originated from families with average or limited socioeconomic level. This is in line with similar studies conducted in our context by Léonie and Bernard [15-17]. They showed that adolescents from families with medium and high socioeconomic level were less prone to short stature compared to those from families with low socioeconomic level $[16,17]$. This seems coherent as socioeconomic level may ameliorate nutrition quality and favor stature development. We found that close to $60 \%$ of families with socioeconomic level as from average to low level, in which children were affected with stunting equally had limited or poor diet. In effect, many studies have reported insufficient dietary factors as a major determinant of growth failure [14, $17,18]$. Moreover, food diversification is a key determinant of growth in children aged 6-16 years [10, 14].

A number of chronic pathological conditions such as sickle cell anemia, cardiac and kidney diseases were reported in 5\% of children presenting stature growth delay. El Hioui et al had earlier demonstrated that stunting in children may be a long-term indicator of chronic undernourishment [3, 14]. This could be due to the fact that chronic diseases lead to increased nutrients' wasting and needs, which if not provided can impact the growth process [20-23].

Some limitations to these results could be related to parents giving wrong information or poorly taken measurements. However, the determination of factors associated with stunting in school children may serve a greater purpose in reducing its prevalence in our communities.

\section{Conclusion}

Even though there has been considerable improvement over the years, stunting still occurs among children in urban communities of Cameroon, as up to $5.4 \%$ of school children in Yaoundé suffer this condition. Short stature may appear as a sign of an underlying pathology and so regular anthropometric measurements and thorough clinical assessment of children may serve for prevention.

\section{Author Contributions}

Authors participated in all steps of the study.

\section{Conflict of Interest}

The authors declare that they have no competing interest.

\section{Ethical Approval}

The study was approved by the Institutional Ethics Committee.

\section{Acknowledgements}

All collaborators to the project.

\section{References}

[1] Albalawi1 NAS, Alsabah1 BAB, Alrefaei AY, Alatawi AMS, Albalawil MS, Al-Enazil ZMMM et al. Short Stature in Children. Egypt J Hosp. 2018; 70 (2): 228-233.

[2] Tanner JM. Growth as a mirror of the condition of the society: Secular trends and clan distinction. In Human Growth: A multidisciplinary Review. A Demirjian editor, London: Taylor and Francis 1986: 3-34.

[3] Tanner JM. Fœtus into Man. Ware, Herts: Casthemead publications 1989.

[4] El Hioui, Ahami A, Aboussaleh Y, Rusinek S. Déficit staturopondéral des élèves d'une école rurale marocaine. Bull. Soc. Pharm. Bordeaux 2008; 147: 61-7.

[5] Kenyo P. Allaitement et état nutritionnel des enfants et des femmes. In Cameroun: Enquête Démographique et de Santé 1998. Edited by Bureau Central des Ressources et des Etudes de Population. Yaoundé 1999: 135-149.

[6] Kalberg J, Jalif F, Lam B, Low L \& Yeung C. Linear growth retardation in relation to three phases of growth. European Journal of Clinical Nutrition 1994; 48: 325-844.

[7] Joint Malnutrition dataset from UNICEF, World Bank and WHO. http: //data.unicef.org/nutrition/malnutrition.html. 2016.

[8] A. Chiabi, PF Tchokoteu, V Takou. Anthropometric measurements of children attending a vaccinating clinic in Yaounde, Cameroon. African Health Sciences 2008; 8 (3): 174-179.

[9] Zayed AA, Beano AM, Haddadin FI, Radwan SS, Allauzy SA, Alkhayyat MM et al. Prevalence of short stature, underweight, overweight, and obesity among school children in Jordan. BMC Public Health. 2016; 16 (1): 1040 .

[10] Soumea T. Etude de la prévalence et des déterminants de la malnutrition chronique chez les enfants en âge préscolaire de la ville de Kenitra. Mémoire. Rabat: Ecole nationale de santé publique. 2013.

[11] Sbaibi R, Aboussaleh Y, Ateillah K, Ahami A. Étude longitudinale de l'état staturo-pondéral des collégiens de la commune rurale Sidi El Kamel (Nord-Ouest Marocain). Antropo. 2013; 29: 125-31.

[12] Camille. Etat nutritionnel d'enfants d'âge primaire à Cotonou (Benin) et à Ouagadougou (Burkina Faso). Not 3035. Minimémoires et séminaires. 2013.

[13] Anastasios P, Konstantinos D, Dimitrios T, Papadimitriou K, Olga K, Andreas F. Characteristics of the short children referred to an academic paediatric endocrine clinic in Greece. Journal of Paediatrics and Child Health; 2011.

[14] Maria W, Edina S, Rosana P. Follow-up of children and adolescents with short stature: the importance of the growth rate. Med J. 2005; 123 (3): 128-33. 
[15] Saengkaew T, McNeil E, Jaruratanasirikul S. Etiologies of short stature in a pediatric endocrine clinic in Southern Thailand. J Pediatr Endocrinol Metab 2017; 30 (12).

[16] Leonie N, Urban J, Nouedoui U, Hans S, Lena S. socioeconomic and gender differences in adolescents' nutritional status in urban cameroon, Africa. Nutritional research 2009; 29: 312-13.

[17] Bernard O, Pagezy H, Bley D. État nutritionnel et environnement pathogène d'enfants d'une population forestière du Sud-Cameroun. Bulletins et mémoires de la Société d'Anthropologie de Paris 2001; 13: 1-2.

[18] Jafari-Adli S, Qorbani M, Heshmat R, Ranjbar SH, Taheri E, et al. Association of short stature with life satisfaction and self-rated health in children and adolescents: the CASPIANIV study. J Pediatr Endocrinol Metab 2016; 29: 1299-306.

[19] Imane C. Evaluation de l'état nutritionnel chez les enfants scolarisés dans les écoles publiques de la ville de rabat: rôle des facteurs socioéconomiques. [Thèse de doctorat en médecine]. Rabat: Faculté de médecine et de pharmacie de Rabat. 2014.

[20] Hussein A, Farghaly H, Askar E, Metwalley K, Saad K, Zahran A et al. Etiological factors of short stature in children and adolescents: experience at a tertiary care hospital in Egypt. Ther Adv Endocrinol Metab. 2017; 8 (5): 75-80.

[21] Mpemba L, Nzingoula S. Anémie et croissance chez l'adolescent congolais drépanocytaire homozygote au CHU de Brazzaville. Bull soc patho 2003; 96 (2): 101-3.

[22] Anissa M, Harry D. croissance de l'enfant diabétique. Rev. med Bruxelles 2010; 31: 77-80.

[23] Lebela J, Chiabi A, Tetanye E. Croissance staturo-pondérale des enfants infectés par le VIH à Yaoundé. Archives de pédiatrie 2010 juin; 17 (6): 94. 